\title{
GENE EXPRESSION OF INTERLEUKIN 8 IN LIVER OF JAPANESE FLOUNDER PARALICHTHYS OLIVACEUS INFECTED WITH EDWARDSIELLA TARDA
}

\author{
Osamu Kurata*, Shinpei Wada \\ Laboratory of Aquatic Medicine, School of Veterinary Medicine, Nippon Veterinary and Life \\ Science University, Tokyo 180-8602, Japan
}

\begin{abstract}
Edwardsiellosis caused by the Gram-negative bacterium Edwardsiella tarda induces hepatitis showing abscess formation in fish. Because the remarkable neutrophil infiltration occurs in the lesions of hepatic abscess, the chemokine interleukin 8 (IL-8) known as a neutrophil chemoatractant is expected to be relevant for the pathogenesis. In this study, we examined the characteristics of IL-8 gene expression in liver of Japanese flounder Paralichthys olivaceus infected with E. tarda.

The experimental infection was performed by bathing of the fishes weighing about $11 \mathrm{~g}$ in a bacterial suspension containing $2 \times 10^{6} \mathrm{CFU} / \mathrm{mL}$ of E. tarda NJB1401 for $10 \mathrm{~min}$. Pathological changes of the liver were investigated by histological analysis using H\&E staining and immunostaining with anti-E. tarda rabbit serum. The response of IL-8 gene expression in the liver was characterized by quantitative RT-PCR assay, which was compared with gene expression of the other inflammatory cytokines, IL- $1 \beta$ and TNF $\alpha$, in the liver and with that in the other organs with lymphoid tissue, the kidney, spleen and intestine.

The liver of infected fish showed upregulation of IL- 8 genes before appearance of $E$. tard $a$ and accumulation of inflammatory cells. On the other hand, the gene expression of IL-1 $\beta$ and TNF $\alpha$ were upregulated after the appearance of E. tarda. Although such a quick response of IL-8 gene expression was also detected in kidney, spleen and intestine of the infected fish, IL-8 gene expression in the liver was more active than that in other organs. In conclusion, the liver was characterized as an organ quickly and actively responding by upregulation of IL-8 gene at the early stage to $E$. tarda infection in Japanese flounder.
\end{abstract}

\section{KEY WORDS}

inflammation, interleukin 8, liver, Paralichthys olivaceus, Edwardsiella tarda

*Corresponding author. Tel.: +81-422-31-4151; Fax: +81-422-31-6796

E-mail address: kurata@nvlu.ac.jp 